\title{
STUDY REGARDING CULTURAL DIVERSITY AND ORGANIZATIONAL BEHAVIOR IN ROMANIA
}

\author{
Buzamat Genoveva ${ }^{307}$ \\ https://doi.org/10.31410/itema.2018.874
}

\begin{abstract}
The necessity of the intercultural steps is evidently related to business globalization and internationalization. The associated social phenomena are strongly influenced by the cultural features, by the communication difficulties between cultures, by the cultural shock and the adaptation to another culture, by the commercial failures and the personal frustrations derived from them. These are but a few examples of challenges that accompany the organizations, whether public or private, on their way towards their goal achievement. The success or the failure of a national economy is strongly influenced by a set of cultural features, not only by the natural or technical factors. In the international literature there are some models that are meant to put an end to the main factors that form a culture and thus difference between the cultures all over the world. The best known and used model is the Geert Hofstende model. It is the standard instrument used to describe the cultural impact over only one economy. This study tries to underline the main components of the Romanian culture. We used our own questionnaire in order to be able to quantify the Romanian culture based on the cultural dimensions of Geert Hofstede.
\end{abstract}

Keywords: Cultural diversity, organizational behavior, Romania

\section{INTRODUCTION}

7 he importance of a culture, as well as its influence upon economy in general and especially management are undeniable in any society, nation or country. The definition of culture has two senses: Firstly ,culture in a restricted sense” which refers to aspects such as art, literature or education. This is the sense the notion culture acquires in most of the western countries and it refers to what is known under the name of ,civilization” i.e. „mind refinement”. Secondly it refers to ,secondary culture”, a notion which is more comprehensive and it is defined as the collective programming of thinking which distinguishes of one group of members (or category of people) from another. [4]. According to Kurt Lewin culture can be defined as ,what a group of people learn along a period of time while they are solving their problems of survival in the external medium as well as the problems of their internal integration." [6]

An essential characteristic of culture is that it is learned, it is not genetically inherited. Culture comes from the social environment of the individual, because culture is a social superindividual phenomenon. Culture is the so called "social inheritance" of a society, where the convictions, the ways and the rules of behavior are transmitted from generation to generation.

\footnotetext{
${ }^{307}$ Banat's University of Agricultural Sciences and Veterinary Medicine "King Michael I of Romania" from Timisoara, Calea Aradului, No 119, Romania ei Timissoara
} 


\section{Material and Method}

In this paper we wanted to present some theoretical aspects referring to the concept of culture as well as some practical methods to identify cultural elements in several business organizations in Romania. For reason of confidentiality we will not give their names. For this we applied a questionnaire with 20 items. The study was made on a sample of 425 people, working in 4 business organizations from the west of Romania. The respondents were randomly chosen from the employees' records of the respective organizations.

\section{Results and Discussions}

In the following lines we present the reflexion in the survey of the five cultural dimensions: Distance to Power, Individualism/Collectivism, Masculinity/Feminity, Avoiding Uncertainty and Long Term Orientation.

Distance to Power This dimension refers to the fact that not all the members of a society are equal and it expresses the attitude of culture towards these inequalities. The distance to power is defined as the extent to which the less powerful/rich members of the institutions and organizations of a country expect and accept that power is distributed unevenly in society.

In addition, we are going to present some of the survey questions on the power distance, as well as the interpretation of the received answers.

Question 1: Do you think the persons who have a good relationship with their superior are favored? (1) usually yes, (2) sometimes, (3) hardly ever/never

Table 1 Frequency of responses at question 1

\begin{tabular}{|c|c|c|c|c|}
\hline Answer options & 1 & 2 & 3 & Total \\
\hline Absolute frequency & 267 & 148 & 10 & 425 \\
\hline Relative frequency (\%) & 62.9 & 34.8 & 2.3 & 100 \\
\hline
\end{tabular}

The results in Table 1 indicate a very large power distance, over $60 \%$ of the respondents choosing the first variant, the others the second one. In other words, Romanians consider that the overrun of the superiors brings about personal benefits.

The fact that in Romania those who try „to fawn upon” their superior take benefits is very strongly argued by the responses distribution of the persons who have different levels of education (The higher the level of education, the higher the number of those who orientated towards the first variant). It is significant that out of the 25 respondents that have a doctor degree, 16 chose the first variant and the others the second. In conclusion, the more educated the respondents are, the more aware they are that success in the Romanian environment is largely based on servility.

Question number 2 If the leader is not right must he be contradicted by the subordinate? (1) a leader mustn't be contradicted, (2) a leader may be contradicted but you will regret later, (3) if the leader is not right he has to be contradicted.

The results in Table 2 describe a large power distance; over $50 \%$ of the respondents chose the first variant, $20 \%$ the second variant and $18 \%$ the last variant. 
Table 2 Frequency of responses at question 2

\begin{tabular}{|c|c|c|c|c|}
\hline Answer options & 1 & 2 & 3 & Total \\
\hline Absolute frequency & 241 & 120 & 64 & 425 \\
\hline Relative frequency (\%) & 53.5 & 28.2 & 18.3 & 100 \\
\hline
\end{tabular}

For your work to be carried out efficiently is authority and power required from the part of the leaders? (1) always, (2) only in certain situations,(3) never.

Table 3 Frequency of responses at question 3

\begin{tabular}{|c|c|c|c|c|}
\hline Answer options & 1 & 2 & 3 & Total \\
\hline Absolute frequency & 319 & 86 & 20 & 425 \\
\hline Relative frequency (\%) & 75 & 20.2 & 4.8 & 100 \\
\hline
\end{tabular}

The bond between this question (Table 3 ) and the power distance is evident in conclusion no explanation is necessary in my opinion.

Question 4 - Should most of the decisions be taken without a preliminary consultation with the other members of the organization? (1) always, (2) sometimes, (3) never.

Table 4 Frequency of responses at question 4

\begin{tabular}{|c|c|c|c|c|}
\hline Answer options & 1 & 2 & 3 & Total \\
\hline Absolute frequency & 283 & 126 & 16 & 425 \\
\hline Relative frequency (\%) & 66.7 & 29.3 & 4 & 100 \\
\hline
\end{tabular}

All these questions describe a large power distance, the majority of the respondents considering normal not to contradict your superior even when he/she is clearly wrong.

This is an extremely faithful indicator of the power distance, as it is a defining element: in a society with a large power distance, the subordinates do not have to be consulted when the decisions are taken and the success in the Romanian environment is greatly conditioned by servility.

\section{Individualism/Collectivism}

Individualism expresses the extent to which society encourages interpersonal relationships and individual achievement. A high level of individualism demonstrates that the focus is on individuality and on individual rights, and there are very weak interpersonal relationships among the society members. The societies with a collectivist nature have a low degree of individualism, where there is very tight links among its members. These cultures strengthen extended families and communities in which each member is responsible for the others. [10]. According to Trompenars, individualism has been described as having a basis of primary orientation towards one's own person, one's own ego, and collectivism as a primary orientation towards the goals and expectations of the community. Trompenars demonstrates that individualism belongs to the societies in which the links among the members are chaotic and it is expected that each member takes care of him/her or of his/her own family.

At the opposite pole there are the collectivist societies in which people are integrated from birth into strong, tight subgroups that continue throughout men's life protecting them in exchange for mutual loyalty. [8] [9] 
The character of the inter-human relationships (individualism/collectivism) is initially formed in the family; they consolidate outside it and they have a strong impact upon culture and organizational behavior. These relationships differ from one society to another through three elements:

- the extent to which members of society depend on each other;

- the number of individuals who entertain somehow intense relationships;

- the criteria according to which relationships between individuals develop - there are cultures in which interpersonal relationships are predetermined, they are based on the assigned status (social class, ethnicity, religious affiliation, generally the belonging to a social group or another) and there are cultures in which relationships between people are set for the sake of it (Hofstede even uses the term chaotic), according to each other's preferences.

\section{Reflection of Individualism in the Survey}

Question $5 \mathrm{Up}$ to what age did you live with your parents? (If you are still living with your parents fill with the age you have now).

Table 5 Frequency of responses at question 5

\begin{tabular}{|c|c|c|c|c|c|}
\hline Answer options & $18-20$ & $21-25$ & $26-35$ & $>35$ & Total \\
\hline Absolute frequency & 156 & 141 & 85 & 43 & 425 \\
\hline Relative frequency (\%) & 36.6 & 33.1 & 20.1 & 13.2 & 100 \\
\hline
\end{tabular}

As you can see, most of today's Romanian youth continue to live with their parents after they become major and complete their studies until very old age. One can notice that extended family is a characteristic of the Romanian society, thus reflecting a low degree of individualism.

Question 6 You are the owner of a small business and you have a free job and your son is unemployed. What do you do? (1) I hire my son without any interview; (2) I make public the job and I hire the best candidate; (3) Under no circumstances do I hire my son in my enterprise.

Table 6 Frequency of responses at question 6

\begin{tabular}{|c|c|c|c|c|}
\hline Answer options & 1 & 2 & 3 & Total \\
\hline Absolute frequency & 256 & 128 & 41 & 425 \\
\hline Relative frequency (\%) & 60.2 & 30.4 & 9.4 & 100 \\
\hline
\end{tabular}

Over half of the respondents answered they would hire their son in their own enterprise on other criteria than competence. This statement is fully supported by what we know about the Romanian organizational practice, where nepotism is an element of normality. A strong differentiation of responses was made by age: young people have moved more towards the first response. I think that in their case the emotional element was much stronger, being in the situation of the son who could be hired (they actually expressed the hope that their parents would help them in such a situation).

Question 7 You have 50 subordinates different in terms of age, gender, nationality, and so on. How do you assign them to smaller teams? (1) I include as many different people as possible in each team; (2) I include as many similar people as possible in each team; (3) I distribute them alphabetically or by lottery; (4) I let them group themselves, according to everyone's preferences. 
Table 7 Frequency of responses at question 7

\begin{tabular}{|c|c|c|c|c|c|}
\hline Answer options & 1 & 2 & 3 & 4 & Total \\
\hline Absolute frequency & 57 & 121 & 85 & 162 & 425 \\
\hline Relative frequency (\%) & 13.5 & 28.3 & 20 & 38.2 & 100 \\
\hline
\end{tabular}

The answers demonstrate a very low level of individualism: the most attractive option for the respondents was the fourth one.

Question 8: Are group decisions usually better than individual decisions? (1) yes; (2) no; (3) I don't know.

Table 8 Frequency of responses at question 8

\begin{tabular}{|c|c|c|c|c|}
\hline Answer options & 1 & 2 & 3 & Total \\
\hline Absolute frequency & 303 & 87 & 35 & 425 \\
\hline Relative frequency (\%) & 71.2 & 20.4 & 8.4 & 100 \\
\hline
\end{tabular}

Most respondents say that decisions taken in group are better than individual decisions.

In conclusion, it has emerged that individualism in Romanians has a low level between $60-70 \%$ of the sample investigated are in favor of the pro - collectivist attitude. The result is natural and logical: if the power distance is large, the index of individualism is small.

\section{Masculinity/Femininity}

Hofstede has defined masculinity based on more arrogant or more modest behavior of individuals. [4]. He called masculine a proud, self-effacing behavior, and feminine a modest, temperamental behavior. In masculine societies the behavior of domination and attempts to excel are appreciated; in the feminine ones, these elements are ridiculed. The members of the latter (regardless of gender) are being taught to be modest and lacking ambition. [4]. Hofstede emphasizes that this attitude is leveling, tracing a person back to a modest condition. [4].

Masculinity measures the degree to which a society retains or not the traditional role of the man to work, to achieve, to have control and power. A high degree of masculinity shows that society is strongly differentiated on the basis of gender; the man has a dominant position in the social and power structures, the woman being controlled, dominated. A low degree of masculinity shows a small measure of differentiation and sexual discrimination; women and men are treated in the same way in all social aspects. [10]. Masculinity does not mean women's disadvantage, but inequality, regardless of its meaning. On the other hand, a certain disadvantage of women exists even in feminine cultures. Women, more often than men, have to do jobs which are uninteresting, subordinate and less well paid. [3].

Despite all the efforts to overcome the traditional clichés, there are still significant differences between the two sexes in Romania: boys are encouraged to be competitive, performing, to assume their independence and dominance, while the girls are induced to be good wives and mothers, dedicated and caring. [5].

\section{Reflection of Masculinity in the Survey}

Question 9 Two of your subordinates contradict each other, and each of them has a solution to a common problem. What do you do? (1) I let them contradict each other to analyze that 
problem as best they can; (2) I intervene in the favor of the one who I think is right; (3) I stop the discussion and find a compromise solution that would please both of them.

Table 9 Frequency of responses at question 9

\begin{tabular}{|c|c|c|c|c|}
\hline Answer options & 1 & 2 & 3 & Total \\
\hline Absolute frequency & 114 & 213 & 98 & 425 \\
\hline Relative frequency (\%) & 26.8 & 50.2 & 23 & 100 \\
\hline
\end{tabular}

To this question the very strong differentiation of the answers was made according to the level of studies, the persons with higher education opting to a much greater extent for the first variant of the answer while they showed stronger rejection of the last variant.

Question 10 Do you consider it normal that, in the same country, some people have wages with several thousand units of currency bigger than others? (1) It is normal, but not in the same organization, (2) It is normal, even within the same organization; (3) there should be low differences between the wages within the same country; (4) salaries should be approximately equal for all citizens of the country.

Table 10 Frequency of responses at question 10

\begin{tabular}{|c|c|c|c|c|c|}
\hline Answer options & 1 & 2 & 3 & 4 & Total \\
\hline Absolute frequency & 51 & 53 & 211 & 110 & 425 \\
\hline Relative frequency (\%) & 12.1 & 12.4 & 49.7 & 25.8 & 100 \\
\hline
\end{tabular}

By formulating this question, we tried to avoid, as much as possible, the emotional involvement. The responses reflect a rather moderate level of masculinity.

Question 11 Is it more important for a man to have a professional career than for a woman? (1) yes; (2)no.

Table 11 Frequency of responses at question 11

\begin{tabular}{|c|c|c|c|}
\hline Answer options & 1 & 2 & Total \\
\hline Absolute frequency & 59 & 366 & 425 \\
\hline Relative frequency (\%) & 18.8 & 86.2 & 100 \\
\hline
\end{tabular}

We see from the frequency of the answers to this question that there is no tendency to create discriminatory practices to the detriment of women.

Question 12 You have a leading position and you want your subordinates to be as efficient as possible. What do you try to offer them first? (1) the possibility to show how valuable they are (creative, intelligent, etc.); (2) better working conditions.

Table 12 Frequency of responses at question 12

\begin{tabular}{|c|c|c|c|}
\hline Answer options & 1 & 2 & Total \\
\hline Absolute frequency & 191 & 234 & 425 \\
\hline Relative frequency (\%) & 47.4 & 52.6 & 100 \\
\hline
\end{tabular}

The answers to the questions in Table 12 confirm the degree of masculinity which seems to be average, the society having a slight feminine tinge. As a curiosity, at this question women turned a little more than men towards the first element of answer that argues the idea of femininity. Romania is a country with a masculine index, but having slight female tonal, meaning members 
of the society look for a collaborative environment and want to support all the members of society, regardless of their contribution.

The advantage of this culture is that we will never need special action to promote women in leadership positions or in political structures because they can move forward by themselves if they want to, because the opposite sex partners do not tend to create discriminatory practices. The disadvantage is that the feminine values of the society determine a lower level of competitiveness of the local organizations compared to the organizations on the foreign market, and the Romanian employees will not positively contribute to the improvement of the situation. Because feminine values appreciate personal spare time and cooperation to the detriment of performance goals, Romanian firms will allow foreign firms to take their place on the market without significant competition.

\section{Uncertainty Avoidance}

This dimension refers to the tolerance of society towards uncertainty and ambiguity, to the feeling of comfort / discomfort that individuals feel when faced with unstructured, new, unknown and unusual situations.

The main aspect of this dimension is how society succeeds in reconciling with the passage of time; in other words, we are all prisoners of the past, present and future, being unpredictable.

Avoiding uncertainty expresses the extent to which people feel themselves threatened by ambiguous situations and the extent to which they try to eliminate these situations by means of the following actions: looking for a safer job, setting out more rules, eliminating different types of behavior and ideas, "establishing" absolute truths, etc. [7] Uncertainty should not be confused with risk.

Some societies encourage their members to accept uncertainty and they do not let them to be negatively affected by this reality. People in such societies tend to accept each day as it comes. They are accustomed to take risks in a relatively easy way. They do not make excessive efforts at work and are relatively tolerant of opinions and behaviors that differ from their own because they do not feel threatened. Such societies are hardly attracted to the fight against uncertainty, and its members generally feel relatively safe.

Other societies stimulate members to try to "defeat" their future. As the future remains, in essence, unpredictable, people have a high level of anxiety, manifested by nervousness, intense emotional states and an increased level of aggression.

\section{Uncertainty Avoidance as Reflected in the Survey}

Question 13 It is important that the requirements and instructions are specified in detail so that employees always know what is expected of them? (1) Yes; (2) No.

Table 13 Frequency of responses at question 13

\begin{tabular}{|c|c|c|c|}
\hline Answer options & 1 & 2 & Total \\
\hline Absolute frequency & 375 & 50 & 425 \\
\hline Relative frequency (\%) & 88.2 & 11.8 & 100 \\
\hline
\end{tabular}

Most respondents preferred clear rules and instructions. 
Question 14 You are a production manager. Do you expect the workers to comply exactly with the manufacturing instructions and procedures? (1) Yes; (2) No.

Table 14 Frequency of responses at question 14

\begin{tabular}{|c|c|c|c|}
\hline Answer options & 1 & 2 & Total \\
\hline Absolute frequency & 101 & 324 & 425 \\
\hline Relative frequency (\%) & 23.8 & 76.2 & 100 \\
\hline
\end{tabular}

The majority of respondents, over $70 \%$, do not expect manufacturing rules and procedures to be observed due to lack of rigor, non-compliance or lack of care.

Question 15 Do you think you should avoid making changes because you might get worse? (1) Yes; (2) No.

Table 15 Frequency of responses at question 15

\begin{tabular}{|c|c|c|c|}
\hline Answer options & 1 & 2 & Total \\
\hline Absolute frequency & 261 & 164 & 425 \\
\hline Relative frequency (\%) & 61.4 & 38.6 & 100 \\
\hline
\end{tabular}

More than $60 \%$ of respondents fear change, the latter being perceived as a considerable stressor, because they have to engage in other relationships, comply with new values and approaches to work.

Question 16 You're late at work, and your boss has argued you. What do you think of him? (1) it's normal to be argue because I'm wrong; (2) he is right to argue, but he could overlook this very little delay; (3) it is not right, a delay of just two or three minutes is normal and should be allowed to anyone.

Table 16 Frequency of responses at question 16

\begin{tabular}{|c|c|c|c|c|}
\hline Answer options & 1 & 2 & 3 & Total \\
\hline Absolute frequency & 43 & 205 & 177 & 425 \\
\hline Relative frequency (\%) & 10.1 & 48.2 & 41.7 & 100 \\
\hline
\end{tabular}

Respondents preferred the latter two variants, indicating an aversion to moderate uncertainty.

\section{Long Term Orientation}

The long-term orientation that has been determined as a result of Michael Bond's and Geert Hofstede's joint researches is the "confucianist" dimension of the time period for which people make plans and expect results and the extent to which they tend to sacrifice the immediate or current outcome for a possible, but more substantial, reward, but in the future [1] The dimension also has traditional, conservative valences, measuring the level at which a society embraces traditional values and progressive thinking [2].

The long-term orientation is characterized, among other things, by perseverance, temperance, holding sentiment of shame, organizing relations through status and preserving them, and shortterm orientation is characterized, among others, by the search for personal security and stability, formal respect for tradition, reciprocity in greetings, favors and gifts. [9] 


\section{Long Term Orientation Reflected in the Survey}

Question 17 You are a manager. How do you deal with smaller, routine activities? (1) I'm trying to leave them to the subordinates; (2) I want to take care of them, but only after I finish with the most important activities; (3) I attach great importance to them because I want everything to be well established.

Table 17 Frequency of responses at question 17

\begin{tabular}{|c|c|c|c|c|}
\hline Answer options & 1 & 2 & 3 & Total \\
\hline Absolute frequency & 175 & 169 & 177 & 81 \\
\hline Relative frequency (\%) & 41.2 & 39.8 & 19 & 100 \\
\hline
\end{tabular}

The data in Table 17 indicates a predominantly long-term orientation; detailed results show that this is particularly the case for men, young people and people with higher education. Question 18 What are the favorite ways of spending leisure time? (1) With my friends; (2) I have a hobby; (3) I rest; (4) I study.

Table 18 Frequency of responses at question 18

\begin{tabular}{|c|c|c|c|c|c|}
\hline Answer options & 1 & 2 & 3 & 4 & Total \\
\hline Absolute frequency & 176 & 36 & 164 & 49 & 425 \\
\hline Relative frequency (\%) & 41.4 & 8.4 & 38.6 & 11.6 & 100 \\
\hline
\end{tabular}

The data in Table 18 indicate a situation closer to the short-term orientation. The first variant of the response and the variant 3 were preferred by the respondents.

Question 19 You are a company's shareholder. How would you proceed with the profit generated by the activity of the organization? (1) I reinvest it; (2) I redistribute it to shareholders.

Table 19 Frequency of responses at question 19

\begin{tabular}{|c|c|c|c|}
\hline Answer options & 1 & 2 & Total \\
\hline Absolute frequency & 189 & 236 & 425 \\
\hline Relative frequency (\%) & 47.8 & 52.6 & 100 \\
\hline
\end{tabular}

Table 19 shows a moderate availability in reinvestment of profit.

Question 20 As a manager of an organization how do you solve current problems? (1) You use the experiments of the past; (2) Try changing some organizational standards.

Table 20 Frequency of responses at question 20

\begin{tabular}{|c|c|c|c|}
\hline Answer options & 1 & 2 & Total \\
\hline Absolute frequency & 261 & 164 & 425 \\
\hline Relative frequency (\%) & 61.3 & 38.7 & 100 \\
\hline
\end{tabular}

In conclusion, it is difficult for Romanians to plan for a very long term that is why they will prefer to bring up the past experiences to solve today's problems.

\section{Conclusions}

In conclusion, the power distance in Romanian is very large, according to an efficient mechanism for preserving and highlighting the differences in status, characterized especially 
by arbitrary leadership and unconditional obedience to hierarchical superiors, with an "indispensable" supplement (required by the need to a higher status). Personnel in organizations in such cultures do not express opinions contrary to the superior and receive orders they execute.

Low individualism, namely collectivism, characterized by waiting for community support, lack of initiative, counterproductive vision of private property and, above all, nepotism and primacy of group interests (irrespective of the criterion of its formation).

Medium-level masculinity with a slight tendency to femininity; unfortunately, from this point of view, the Romanian culture is not homogeneous but contains a set of extremely masculine tendencies on the one hand (the pronounced differentiation between the behaviors of the two sexes) and on the other hand a set of pronounced feminine tendencies (egalitarianism, negative vision of wealthy people, convenience, etc.).

It is a good thing that we will never need special actions to promote women in leadership positions or in political structures because they can move forward alone if they want because opposite sex partners do not tend to create discriminatory practices for women.

The religion of a country can be a source of feminine or masculine values, depending on how it perceives gender differences. Orthodox religion, predominant in Romania, is more inclined to the complementarities of the sexes rather than to the subordination of the woman to her husband.

The avoidance of uncertainty is at a high level, characterized as above, by the opposite: on the one hand, strong avoidance elements (the social impact of religion, the need for the most powerful control authorities over citizens), on the other hand, elements of accepting uncertainty (laziness, carelessness, lack of rigor).

Population has a high degree of anxiety about the future and prefers today's safety compared to tomorrow's uncertainty.

The average value of long-term orientation, is a consequence of both the traditionalism that exists at a high level in culture.

\section{REFERENCES}

[1] Leung, K., \& Bond, M. H. (2009). (Eds.). Psychological aspects of social axioms: Understanding global belief systems. New York: Springer SBM.

[2] Nicolae, Aurelian, Bibu. (2002) Management comparat. Abordare intercultulă, o abordare modernă Editura Mirton Timișoara, pp. 28-29

[3] Daum, Qce (1995). Mentalitatea suedeză, Editura Humanitas, Bucureşti

[4] Geert, Hofstede ( 1996) Managemtul Structurilor multiculturale, Software-ul gândirii, Ed. Economică București, pp 99,109-110

[5] Petre, Iluț, (2000) Iluzia localismului și localizarea iluziei, Ed. Economică, Iași, pp 185.

[6] Kurt, Lewin (2001) Frontiere în dinamica gruurilor, Ed Ploirom bucurelti pp. 29

[7] Fred Luthans, (1992). Organizational Behavior, McGraw Hill International Editions, pp 588.

[8] Fons, Trompenaars (1990) L`Entreprise multinationele, Laurant du Marsil, Paris pp, 154

[9] Ovidiu, Nicolescu, (1997). Management comparat, Editura Economică, Bucureşti pp 52

[10] (http://www.geert-hofstede.com 